\title{
Heterochromatin differentiation in holocentric chromosomes of Rhynchospora (Cyperaceae)
}

\author{
André L.L. Vanzelal and Marcelo Guerra ${ }^{2}$
}

\begin{abstract}
Holocentric chromosomes of six species of Rhynchospora, . ciliata, . pubera, $R$. riparia and $R$. barbata $(2 \mathrm{n}=10), R$. nervosa $(2 \mathrm{n}$ $=30)$ and $R$. globosa $(2 \mathrm{n}=36)$, were stained with $\mathrm{CMA}_{3} / \mathrm{DAPI}$ fluorochromes or treated with C-banding and sequentially stained with Giemsa or $\mathrm{CMA}_{3} / \mathrm{DAPI}$. Variability in banding pattern was found among the species studied. Heterochromatin was observed on terminal and interstitial chromosome regions, indicating that the holocentric chromosomes of Rhynchospora show a heterochromatin distribution pattern similar to those plant monocentric chromosomes.
\end{abstract}

\section{INTRODUCTION}

Heterochromatic sequence localization by banding techniques has contributed to our knowledge of chromosome organization, permitting discrimination between morphologically similar chromosomes, and aiding in establishing evolutionary relationships between closely related taxa. Few studies exist on the heterochromatin distribution pattern in holocentric chromosomes of plants. Initial research was done on the genus Luzula (Juncaceae) by Ray and Venketeswaram (1978) and Collet and Westerman (1984), who found interspersed among the euchromatin a variable number of C-bands, which fused during metaphase condensation. Thus, in prophase and prometaphase the band number was much larger than in metaphase. A similar situation was described for insect holocentric chromosomes (see Giles and Webb, 1972; Manicardi et al., 1991; Manicardi and Gautam, 1994).

Other work has demonstrated that holocentric chromosomes can exhibit defined heterochromatic blocks in telomeric regions (Panzera et al., 1992) as well as in telomeric and interstitial regions, e.g., in the Heteroptera Nezara viridula (Camacho et al., 1985). A similar case was reported by Sheikh and Kondo $(1995,1996)$ for several species of Drosera (Droseraceae), where interstitial C-bands were found in a few chromosomes and $\mathrm{CMA}_{3} /$ DAPI bands preferentially in telomeric regions.

The holocentric nature of Rhynchospora chromosomes has been discussed (Vanzela et al., 1996; Luceño et al., 1998). However, little information exists about the behavior and organization of the highly repetitive DNA in those chromosomes. The present article reports the heterochromatin distribution pattern in holocentric chromosomes of six Brazilian species of Rhynchospora, using three distinct chromosome banding methods.

\section{MATERIAL AND METHODS}

Six different species of the genus Rhynchospora ( $R$. ciliata, $R$. pubera, $R$. riparia, $R$. barbata, $R$. nervosa and $R$. globosa) were studied. The voucher specimens collected in Northeastern and Southern Brazil are kept in the Universidade Federal de Pernambuco herbarium (Table I).

Root tips were pretreated with $2 \mathrm{mM} 8$-hydroxyquinolin for $24 \mathrm{~h}$ and further fixed in Carnoy $(3: 1, \mathrm{v} / \mathrm{v})$ for 1-24 h. Tests were digested for $3 \mathrm{~h}$ in a mixture of $4 \%(\mathrm{v} /$ v) cellulase and $40 \%(\mathrm{v} / \mathrm{v})$ pectinase, and squashed in a drop of $45 \%$ acetic acid. The coverslip was removed in liquid nitrogen and, after three days, the chromosomes were treated in three different ways. In the first treatment, $R$. ciliata and $R$. barbata samples were directly stained with a drop of $0.5 \mathrm{mg} / \mathrm{ml} \mathrm{CMA}_{3}$ in McIlvaine buffer, $\mathrm{pH}$ 7.0/distilled water (1:1) and $2.5 \mathrm{mM} \mathrm{MgCl}_{2}$ for $1 \mathrm{~h}$, washed in distilled water and stained with a drop of $2 \mu \mathrm{g} / \mathrm{ml}$ DAPI in McIlvaine buffer, $\mathrm{pH} 7.0$, for $30 \mathrm{~min}$, as described by Schweizer (1976). In the second, $R$. ciliata, $R$. barbata and $R$. nervosa samples were treated according to the Cbanding procedure $\left(45 \%\right.$ acetic acid at $60^{\circ} \mathrm{C}$ for $10 \mathrm{~min}$, $5 \% \mathrm{BaOH}$ at room temperature for $10 \mathrm{~min}$ and $2 \mathrm{xSSC}, \mathrm{pH}$ $=7.0$, at $60^{\circ} \mathrm{C}$ for $1 \mathrm{~h}$ and $20 \mathrm{~min}$ ) and stained with $2 \%$ Giemsa, according to Schwarzacher et al. (1980). In the third treatment, $R$. ciliata, $R$. pubera, $R$. riparia and $R$. globosa samples were processed for C-banding, as mentioned above, and stained with $\mathrm{CMA}_{3} / \mathrm{DAPI}$ (Barros e Silva and Guerra, 1998).

Materials stained with $2 \%$ Giemsa were mounted with Entellan (Merck) and those stained with fluorochromes were mounted in glycerin:McIlvaine buffer $(1: 1, \mathrm{v} / \mathrm{v})$ and $2.5 \mathrm{mM}$ $\mathrm{MgCl}_{2}$. Those stained with Giemsa were analyzed with an optical microscope, and photos were taken with Imagelink 
HQ 25 ASA Kodak film. Those stained with fluorochromes were examined using epifluorescence microscopy and photographed with T-MAX 400 ASA Kodak film.

\section{RESULTS}

Three different species were analyzed with C-banding: Rhynchospora ciliata $(2 \mathrm{n}=10)$ showed the highest number of terminal and interstitial blocks in almost all chromosome pairs (Figure 1a), R. barbata $(2 \mathrm{n}=10)$ exhibited a small pair of interstitial dots in each chromosome, in addition to terminal blocks (Figure 1b), and $R$. nervosa, with $2 \mathrm{n}=30$, presented heterochromatic blocks in some terminal and interstitial regions (Figure 1c).

The $\mathrm{CMA}_{3} / \mathrm{DAPI}$ staining revealed terminal and interstitial regions $\mathrm{CMA}_{3}{ }^{+} / \mathrm{DAPI}^{0}$ (DAPI neutral) in $R$. ciliata prometaphases (Figure $2 \mathrm{a}$ and $\mathrm{b}$ ), and $\mathrm{CMA}_{3}{ }^{+} / \mathrm{DAPI}^{-}$interstitial dots in $R$. barbata metaphases (Figure $2 \mathrm{~g}$ ). These signals corresponded to those obtained by $\mathrm{C}$-banding.

The C-banding procedure, followed by $\mathrm{CMA}_{3} / \mathrm{DAPI}$ staining, also revealed variations in number and type of heterochromatic sequences among the four analyzed species. Rhynchospora pubera $(2 \mathrm{n}=10)$ exhibited three chromosome pairs with $\mathrm{CMA}_{3}{ }^{+}$terminal regions. One of these showed a larger and brighter signal, while the others showed weaker signals (Figure $2 \mathrm{~d}$ and e). $R$. riparia, with $2 \mathrm{n}=10$, exhibited $\mathrm{CMA}_{3}{ }^{+}$blocks in four chromosome pairs. In two of these, blocks were only terminal, while in the two other pairs, bands appeared in terminal and interstitial positions (Figure 2f). DAPI bands were not observed in these two species. R. ciliata (Figure 2c) showed a band pattern similar to that obtained using C-banding and $\mathrm{CMA}_{3} /$ DAPI staining. $R$. globosa was the only species that showed different patterns of $\mathrm{CMA}_{3}$ and DAPI bands. DAPI ${ }^{+}$and $\mathrm{CMA}_{3}{ }^{+}$signals occurred in different terminal or subterminal regions on most of the chromosomes (Figure 2h). Besides, $\mathrm{CMA}_{3}{ }^{+}$bands always showed an appearance of small dots (Figure 2i), as in $R$. barbata. Interphasic nuclei showed randomly distributed $\mathrm{CMA}_{3}{ }^{+}$and $\mathrm{DAPI}^{+}$ blocks (Figure 2f, g, i, and h, respectively).

\section{DISCUSSION}

The $\mathrm{CMA}_{3} / \mathrm{DAPI}$ staining, Giemsa C-banding and Cbanding followed by $\mathrm{CMA}_{3} / \mathrm{DAPI}$ staining revealed three different heterochromatin types in Rhynchospora holocentric chromosomes. The first type, characterized by $\mathrm{CMA}_{3}{ }^{+} / \mathrm{DAPI}{ }^{0}$ in $R$. ciliata, coincided with those obtained by Giemsa banding and was similar to that found in Drosera puchella and D. scorpioides holocentric chro-

Table I - Type and distribution of heterochromatin blocks on chromosomes of six species of Rhynchospora.

\begin{tabular}{|c|c|c|c|c|c|c|c|}
\hline Species & Localities & UFP & $2 \mathrm{n}$ & C-band & $\mathrm{CMA}_{3}{ }^{+} / \mathrm{DAPI}^{0}$ & $\mathrm{CMA}_{3}^{+} / \mathrm{DAPI}^{-}$ & $\mathrm{CMA}_{3}{ }^{-} / \mathrm{DAPI}^{+}$ \\
\hline R. ciliata & Recife-PE* & 09337 & 10 & $\mathrm{~T}$ and $\mathrm{I}$ & $\mathrm{T}$ and $\mathrm{I}$ & $\mathrm{T}$ & -------- \\
\hline R. pubera & Recife-PE & 11181 & 10 & ------- & ------- & $\mathrm{T}$ & ------- \\
\hline R. riparia & Recife-PE & av26pe & 10 & ------- & ------- & $\mathrm{T}$ and $\mathrm{I}$ & -------- \\
\hline R. barbata & Gravatá-PE & av34pe & 10 & ------- & -------- & $\mathrm{T}$ and $\mathrm{I}$ & ------- \\
\hline R. nervosa & Ipojuca-PE & 11136 & 30 & $\mathrm{~T}$ and $\mathrm{I}$ & -------- & -------- & -------- \\
\hline R. globosa & Tibagi-PR* & av410pr & 36 & -------- & --------- & $\mathrm{T}$ and $\mathrm{I}$ & $\mathrm{T}$ and $\mathrm{I}$ \\
\hline
\end{tabular}

*- PE and PR correspond to Brazilian States. UFP = Herbarium of the Universidade Federal de Pernambuco, Recife, PE, Brazil. $T=$ Terminal bands. $I=$ Interstitial bands.

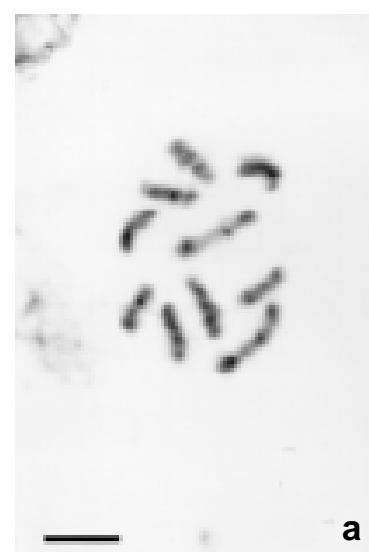

a
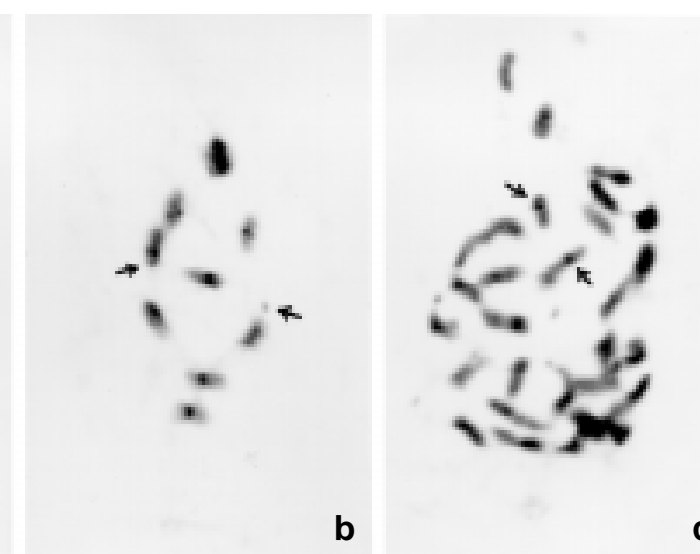

Figure 1 - Giemsa C-banding in mitotic chromosomes of Rhynchospora. a) $R$. ciliata with $2 \mathrm{n}=10$. b) $R$. barbata with $2 \mathrm{n}=10$. Arrows indicate terminal bands. c) $R$. nervosa with $2 \mathrm{n}=30$. Arrows indicate terminal and interstitial bands. Bar represents $5 \mu \mathrm{m}$. 

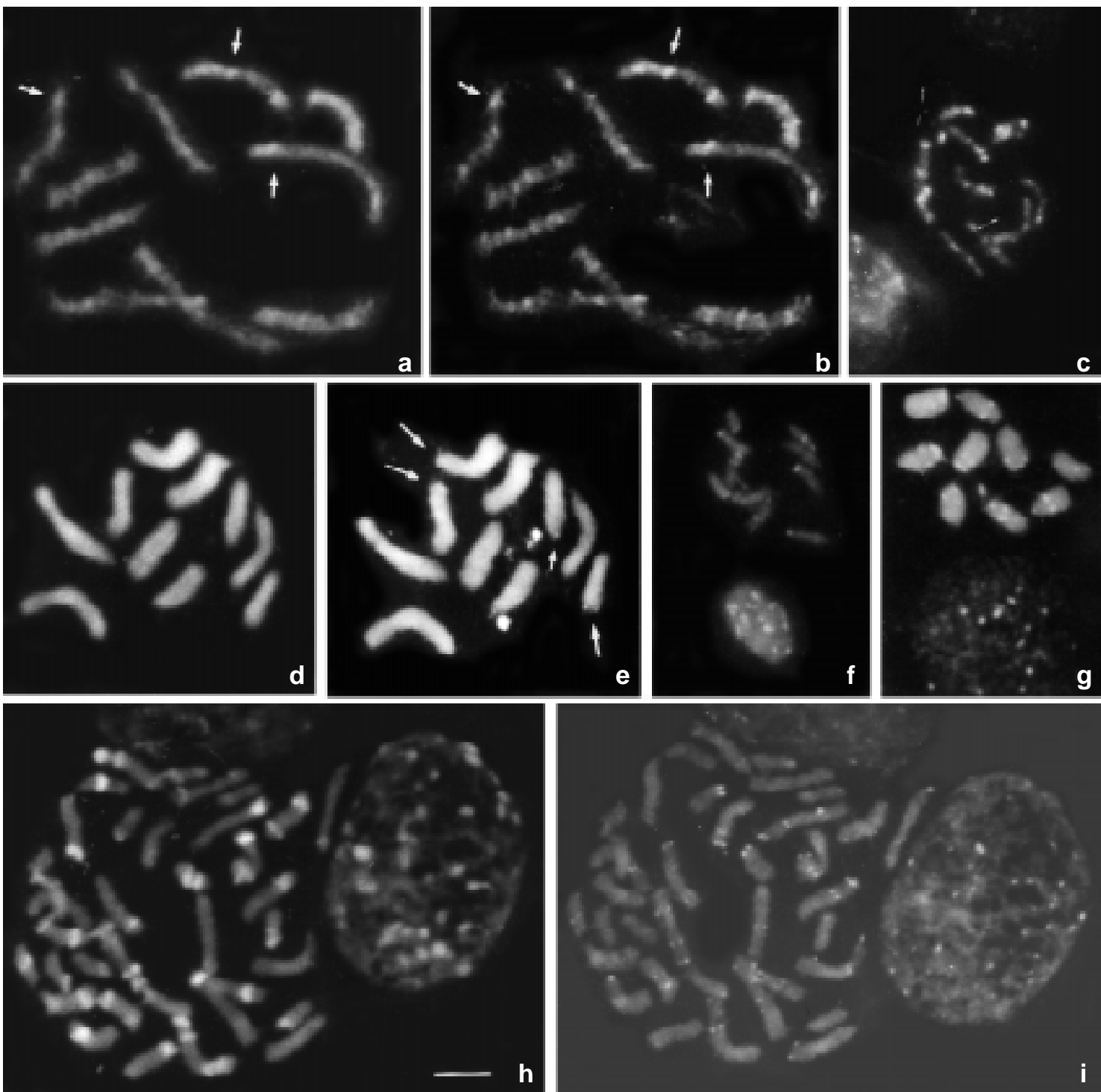

Figure 2 - CMA /DAPI banding in mitotic chromosomes of Rhynchospora. $\mathbf{a}$ and $\mathbf{b})$ Prometaphase in $R$. ciliata $(2 \mathrm{n}=10)$ directly stained with DAPI and $\mathrm{CMA}_{3}$, respectively. Arrows indicate blocks DAPI $/ \mathrm{CMA}_{3}{ }^{+}$. c) Chromosomes of $R$. ciliata stained with $\mathrm{CMA}_{3}$ after C-banding procedure. $\mathbf{d}$ and e) Mitotic metaphase in $R$. pubera with $2 \mathrm{n}=10$. Arrows show $\mathrm{CMA}_{3}{ }^{+}$blocks. f) Mitotic chromosomes in $R$. riparia $(2 \mathrm{n}=10)$ stained with $\mathrm{CMA}_{3}$ after C-banding procedure. $\mathbf{g})$ Mitotic chromosomes in $R$. barbata $(2 \mathrm{n}=10)$ stained with $\mathrm{CMA}_{3}$. h) Mitotic chromosomes of $R$. globosa $(2 \mathrm{n}=36)$ stained with DAPI. i) Mitotic chromosomes of $R$. globosa stained with $\mathrm{CMA}_{3}$. Bar represents $5 \mu \mathrm{m}$.

mosomes (Sheikh and Kondo, 1996). These regions could correspond to heterogeneous heterochromatin sites, where GC-rich segments are intercalated with AT-rich ones, as described by Guerra (1989) and Cuellar et al. (1996). The second type, $\mathrm{CMA}_{3}{ }^{+} / \mathrm{DAPI}^{-}$bands present in most of the species, and the third type, $\mathrm{CMA}_{3}^{-} / \mathrm{DAPI}^{+}$blocks, found only in R. globosa, seem to correspond to GC-rich and AT-rich DNA sequences, respectively (Schweizer, 1976).

Comparative band pattern analysis in these six species showed that size and location of heterochromatic segments were very variable. Heterochromatin may occur as large or small blocks ( $R$. pubera and $R$. riparia), as few or multiple blocks along the chromosomes $(R$. barbata and $R$. globosa) and in terminal and/or interstitial regions.
This heterochromatin segment distribution pattern resembles that observed in some plant groups (see Schweizer and Ehrendorfer, 1983). The data presented here differ from those observed for Luzula holocentric chromosomes (Ray and Venketeswaram, 1978; Collet and Westerman, 1984).

The variation observed in the holocentric chromosome banding patterns of Rhynchospora could be explained by the presence of different initiation and amplification heterochromatin sites (Peacock et al., 1981), possibly with dispersion by gene conversion or unequal crossing-over (Schweizer and Ehrendorfer, 1983) or by an equilocal dispersion mechanism similar to that proposed by Schweizer and Loidl (1987), for monocentric chromosomes. 
Terminal $\mathrm{CMA}_{3}$ bands were observed in one or more chromosomes of all species studied. At least in R. ciliata and $R$. pubera, the $\mathrm{CMA}_{3}$ blocks seem to correspond in position to rDNA sites described by Vanzela et al. (1998) through in situ hybridization. Therefore, some or all $\mathrm{CMA}_{3}$ terminal bands observed in $R$. riparia, $R$. barbata and $R$. globosa could possibly be related to the NOR. Similar results were found for Drosera (Sheikh and Kondo, 1995).

These results suggest that no single typical pattern of heterochromatic segment distribution is present on holocentric chromosomes of Rhynchospora, in contrast with the conclusion presented by Collet and Westerman (1984) for Luzula holocentric chromosomes, i.e., "highlyrepeated DNA is not localized in single blocks, but is interspersed amongst the euchromatin". Band pattern variations may be more related to structural rearrangements, as in monocentric chromosomes (Deumling and Greilhuber, 1982; Schweizer and Ehrendorfer, 1983), rather than reflecting kinetochore organization on the chromosomes.

\section{ACKNOWLEDGMENTS}

The authors are grateful to CAPES, CNPq, BNB and FACEPE for financial support. Publication supported by FAPESP.

\section{RESUMO}

Cromossomos holocêntricos de seis espécies de Rhynchospora $(R$. ciliata, $R$. pubera, $R$. riparia e $R$. barbata $(2 \mathrm{n}=$ $10), R$. nervosa $(2 \mathrm{n}=30)$ and $R$. globosa $(2 \mathrm{n}=36))$ foram corados com os fluorocromos $\mathrm{CMA}_{3} / \mathrm{DAPI}$ ou tratados para bandeamento $\mathrm{C}$ e seqüencialmente corados com Giemsa ou $\mathrm{CMA}_{3}$ /DAPI. Variabilidade no padrão de bandas foi encontrada entre as espécies estudadas. A heterocromatina foi observada em regiões terminais e intersticiais dos cromossomos, indicando que os cromossomos holocêntricos de Rhynchospora mostram um padrão de distribuição de heterocromatina similar àqueles dos cromossomos monocêntricos de plantas.

\section{REFERENCES}

Barros e Silva, A.E. and Guerra, M. (1998). Influência do processo de bandeamento C sobre a coloração com fluorocromos CMA e DAPI em Emilia sonchifolia e Zephyrantes sp. Genet. Mol. Biol. 21: 161 (Abstract).

Camacho, J.P.M., Belda, J. and Cabrero, J. (1985). Meiotic behaviour on the holocentric chromosomes of Nezara viridula (Insecta-Heteroptera) analyzed by C-banding and silver impregnation. Can. J. Genet. Cytol.
27: 490-497.

Collet, C. and Westerman, M. (1984). Interspersed distribution patterns of C-bands and satellite DNA in the holocentric chromosomes of Luzula flaccida (Juncaceae). Genetica 63: 175-179.

Cuellar, T., Belhassen, E., Fernández-Calín, B., Orellana, J. and Bella, J.L. (1996). Chromosomal differentiation in Helianthus annuus var. macrocarpus: heterochromatin characterization and rDNA location. Heredity 76: 586-591.

Deumling, B. and Greilhuber, J. (1982). Characterization of heterochromatin in different species of the Scilla siberica group (Liliaceae) by in situ hybridization of satellite DNAs and fluorochrome banding. Chromosoma 84: 535-555.

Giles, E.T. and Webb, G.C. (1972). The systematics and karyotype of Labidura truncata Kirby, 1903 (Dermaptera-Labiduridae). J. Aust. Ent. Soc. 11: 245-256.

Guerra, M. (1989). The chromosomes of Azima tetracantha (Salvadoraceae). Pl. Syst. Evol. 168: 83-86.

Luceño, M., Vanzela, A.L.L. and Guerra, M. (1998). Cytotaxonomic studies in Brazilian Rhynchospora (Cyperaceae), a genus exhibiting holocentric chromosomes. Can. J. Bot. 76: 440-449.

Manicardi, G.C. and Gautam, D.C. (1994). Cytogenetic investigations on the holocentric chromosomes of Tetraneurella akinire (Sasaki) (Homoptera, Pemphigidae). Caryologia 47: 159-165.

Manicardi, G.C., Gautam, D.C., Bizzaro, D., Guicciardi, E., Bonvicini, P.A.M. and Bianchi, U. (1991). Chromosome banding in Aphids: G, C, AluI and HaeIII banding patterns in Megoura viciae (Homoptera, Aphidiae). Genome 34: 661-665.

Panzera, F., Álvarez, F., Sánchez-Rufas, J., Pérez, R., Suja, J.A., Scvortzoff, E., Dujardin, J.P., Estramil, E. and Salvatella, R. (1992). C-heterochromatin polymorphism in holocentric chromosomes of Triatoma infestans (Hemiptera-Reduviidae). Genome 35: 1068-1074.

Peacock, W.J., Dennis, E.S. and Gerlach, W.L. (1981). Satellite DNA change and stability. Chromosomes Today 7: 30-41.

Ray, J.H. and Venketeswaram, S. (1978). Constitutive heterochromatin distribution in monocentric and polycentric chromosomes. Chromosoma 66: 341-350.

Schwarzacher, T., Ambros, P. and Schweizer, D. (1980). Application of Giemsa banding to orchid karyotype analysis. Pl. Syst. Evol. 134: 293-297.

Schweizer, D. (1976). Reverse fluorescent chromosome banding with chromomycin and DAPI. Chromosoma 58: 307-324.

Schweizer, D. and Ehrendorfer, F. (1983). Evolution of C-band patterns in Asteraceae-Anthemideae. Biol. Zbl. 102: 637-655.

Schweizer, D. and Loidl, J. (1987). A model for heterochromatin dispersion and the evolution of C-band patterns. Chromosomes Today 9: 61-74.

Sheikh, A.S. and Kondo, K. (1995). Differential staining with orcein, Giemsa, CMA and DAPI for comparative chromosome study of 12 species of Australian Drosera (Droseraceae). Am. J. Bot. 82: 1278-1286.

Sheikh, A.S. and Kondo, K. (1996). Comparative C-banding and fluorescent-banding analysis of seven species of Drosera (Droseraceae). Cytologia 61: 383-394.

Vanzela, A.L.L., Guerra, M. and Luceño, M. (1996). Rhynchospora tenuis Link (Cyperaceae): a species with the lowest number of holocentric chromosomes $(\mathrm{n}=2)$. Cytobios 88: 219-228.

Vanzela, A.L.L., Cuadrado, A., Jouve, N., Luceño, M. and Guerra, M. (1998). Multiple locations of the rDNA sites in holocentric chromosomes of Rhynchospora (Cyperaceae). Chromosome Res. 6: 345-349.

(Received September 28, 1999) 